\title{
The 'Outer Child' as a form of Subjective Experience of the Lifeworld
}

\author{
Dr. G.V. Loewen \\ Department of Sociology, STM College, University of Saskatchewan, 1437 College Drive, \\ Saskatoon, SK Canada S7N 0W6 \\ Email: gloewen@stmcollege.ca
}

Accepted: July 03, 2012 Published: August 31, 2012

Doi:10.5296/jsr.v3i2.2330 URL: http://dx.doi.org/10.5296/jsr.v3i2.2330

\begin{abstract}
Beyond the singular appearance of physical being, the idea of personality and uniqueness, and the duplicitous selves that are divided along the lines of the division of social role labor and performance, there is a form of subjective experience in the world that allies itself with our memory of what we were before we were all of these other things. This is the 'outer child', and it represents a form of life that at once partakes in the rationalization of the self as an object in the world of objects, but declines to be entirely rational. Five aspects of the character of the outer child are analyzed and discussed: it's experiential testimony rather than its truthfulness; its lack of studied subject and formal method of perceptions; the grounding of its beliefs in a form of naivete; its ambiguous relationship with instrumental reason, and; its sense that the self is possessed of itself. A set of canonical and key texts is examined to understand how these aspects of subjective experience are combined into a unique but unquiet rationality.
\end{abstract}

Keywords: self, child, rationality, lifeworld, subjectivity, object

\section{Introduction}

It is commonplace to imagine that the self is one thing. At most, we are willing to accept that our diverse roles allow us to play-act different aspects of ourselves. This taking for granted of the world of singular being is both an interpretive and an ethical error. One, because we often misinterpret the source of our motives in taking action in the world, and two, to do so is to make ourselves false and to commit to rewriting our own histories after the manner of political convenience; what is necessary for the moment, to 'get things done', overlays all of the diversity of knowing that we too have lived and cannot erase those lives. We may harbor ironic ressentiment against the unconscious. Why should it determine the form of thought? Can it itself not be fulfilled with a dialogue. Indeed, it is more likely that we undertake a 
conversation with the unconscious, rather than it giving us the Kantian parerga from the heights, as it were, or perhaps from the depths. This dialogue is, however, crucial to our being. If the unconscious is not entirely the form of thinking which belies and underlies all thought the rational concept of the source of the irrational is just as good a working definition here then the form which the dialogue with it takes is also a template for our dialogue with history, and for the much vaunted 'conversation of mankind' which, as we shall see below, founders on its desire to live up to its hype. History, the unconscious, and rationality, these three interlocutors must also be brought into intimate contact with one another, and the only beings who can do this is we ourselves through a consciousness which is at once shaped and shifted by all three of them. Yet this is what authentic dialogue is all about - one is changed through the encounter, and one opens up oneself and risks what has been the existential case. This opening up is kindred to the cutting out we have discussed, and this risk is the same kind of risk that confronts potential servitude to know its own freedom.

\section{Not Truths but Experiences}

If there is a child self who can appear in an artistic allegory in the very act of the reason of unreason, the cutting loose of freedom and the letting flow of the life-blood of being, then there is also an 'outer child', whose guises must be carefully investigated in order to establish their relationship to what we might hope will free us. They have at least five forms, including a) this child's rejection of Truth in favor of experiences, b) the rejection of methods and of the singularity of subject, c) their naivety regarding beliefs and the landscape of believing - that is, what do beliefs do and where do they adhere? - d) their questioning of rationalities, and e) their inclination towards possession and possessiveness. Some of these will lend to us an authenticity that the child self whose goal is letting loose the reason of unreason as against the death's head grin of systematic and instrumental rationality, and some of them will hinder this cause. Which is which and why so, will be our question for this section.

The rejection of Truth in favor of experience has a 'hippyesque' intonation, but such a preference has a lengthy history in many diverse cultures. The tired but time-honoured interlocution between Platonic style ideas and empiricities is still current in the sense that we still investigate the cosmos with the idea that here might well be a truth about it that can be known not only by human beings, but through the use of reflective reason and patient unbiased observation alone. Even if this is to be the case, and we cannot now know that it is, we are very aware that such an idea about ideas has not been fulfilled by historical studies, either of science or of philosophy. What we know is that knowledge changes, sometimes radically, over time, and sometimes over rather short spaces of time. We expect our knowledge, or parts thereof, to become obsolete in a generation and no longer in a lifetime. As the elites of this world live longer and longer, we also expect that the world itself, and as a whole, that we grew into will cease to exist and that we will become as living relics from a different age. No doubt our elders even at this time feel that the world is 'passing them by' in some unalterable and yet tragically poignant sense. At the same time, human lives are often seen as secondary and relatively trivial cases when juxtaposed with human knowledge. this is 
perhaps the first and capital ethical mistake of rationality and its career, and suggests to us that the morality of this idea has at least two types; one that allows itself to flourish as an ideal, an upstanding citizen in the world of ideas, and a second that falls on its face when confronted with the human condition. When we compare these two standards of what is moral, the Platonic style idea of truths which were universal and prior to human experience confronts the human experience of living in a diverse and mutable world: "Thus the ancient notion of tradition-independent truths [ ] which had run into the problem of cultural variety was replaced by the somewhat less ancient notion of tradition-independent ways of finding truths [ ]. And being rational and using reason now meant using these ways and accepting their results." (Feyerabend op. cit. 8 italics the text's). There at first appears to be little difference in the child's eye view that accepts something as given and immutable - as all of us are told as children, after all, that what is 'not allowed' is almost the same as what is 'impossible' - and a viewpoint that says that the truth is 'out there' and there are specific ways of getting at it that everyone must use. Those who do not use these ways will not find the truth, and it is as simple as that. Children do not at first realize that the adults who are telling them these kinds of things have already constructed the world to their own cultural imaginations, or have had it constructed by their predecessors, and are merely passing on the most convenient manner of doing things in their world, and not necessarily the world of the child. It is o different when learning the discourses of science or philosophy, as they are not only new languages, none of which are given in the primary socialization of any culture, but are also 'worlds' that have been set up beforehand and then begin, navel like, perhaps, to investigate themselves: "Intellectuals interested in perpetuating the routine provide it with a 'foundation' by showing that and how it leads to important results [ ]. Far-reaching practices and views have been supported by a 'reality' that was shaped by them in the first place." (ibid:107). No differently than the wider culture in which these ides or even social movements find their home and their birthplace, serious speech act discourses shift or collapse under their own weight. The history of science is stereotypically fraught with the problem of abnormality, where 'normal science' is confronted with data that do not 'fit', and the gravity of these at first anomalies sometimes suddenly implodes the system of knowledge, and sometimes its 'ways of finding truth' as well: "...creative developments in history possess their own inherent contradictions, which eventually disrupt or devastate them from within." (Blackburn op. cit. 2). More importantly, the very structure of discourse - the manner of categorizing the object realm, for instance; there is no 'Ministry of Small Ball Games' anywhere but in the Chinese government, for example - can radically shift in the course of a generation, sparking the creation of new sciences. But how can a science itself be new, if there were already tradition independent ways of doing science?

Perhaps it is not surprising, given at least the reciprocity of the social world of objects and those human beings charged with its study, that developments in the intellectual or discursive sphere react to or follow from not only their own pedigree's development but from more worldly changes occurring around them. Thus evolutionary theory forms itself in a historical milieu where the notion of change itself has become first and foremost, and the notion of adaptation and thus survival are plainly to be seen in the advent of industrial capital and its 
workforces, urbanization, social class, production and consumption. At the same time, such practices of the new mode of production were hardly perfected at this time. There was much waste and offal, with a variety of new means that either led to nothing or were forced to wait until either technologies caught up with the vision of the product, or vice-versa, where there was a new technology that appeared at first to have no application. All of this should sound familiar, and its 'naturalization' took on a organismic form: "Darwin drew attention to numerous 'mistakes': life is not a carefully planned and meticulously performed realization of clear and stable aims; it is unreasonable, wasteful, it produces an immense variety of forms and leaves it to the particular stage it has reached [ ] to define and eliminate the failures." (Feyerabend op. cit. 188). Is it surprising that today, in later capital, and within the 'developed' nations, that our understanding of organismic evolution and of Darwin and others has shifted to think of it in more stable ways, or yet further, that there has been a reassertion of reason within evolution, either hailing from advanced genetics or from the seemingly retrogressive position of a posited divine watchmaker. 'Intelligent Design' is a reflection of the attempted social stability of latter day capital; its saints are the saints of the tax system, of social welfare, and of government incentives.

Luxury too has its say. The predominance of things we do not need, with production first outstripping consumption around 1925 - the new theory of advertising, courtesy John Watson, appears in that very year, the Phoebus circle initiates its desires for planned obsolescence and infinite consumption in the decade following from this mid-Twenties, etc. - and by 1950, with Riesman's trenchant critique of such a society, discourse must come to terms with this presence as well. Understanding the dangers of excess becomes a necessity. reversing the idea that it is need that produces risk, Bataille famously suggests that what threatens humanity in its cultural variety is the over-production of energies and resources without outlet. We must consume and expend to no end and to no purpose to live on: "Beyond our immediate ends, man's activity in fact pursues the useless and infinite fulfillment of the universe." (Bataille op. cit. 21). The metaphysical arc of such human action aside for the moment, it is clear that at the very least, mechanical societies do not pursue ends that have no purpose, and indeed, social solidarity might well cover most of Bataille's own examples, from the potlatch to human sacrifice, in more complex societies. He does immediately add, however, that "Of course, the error that results from so complete a disregard does not concern man's claim to lucidity." (ibid:21). No, it is only in our society, that of over-productive capital, that Bataille's claims regarding the accursed share take on their fullest meaning, and it was only by the mid-twentieth century that such forces could be assembled and studied to any great degree - Bataille's manuscript text of the first volume of the work critiqued actually dates form c. 1952. From quite different discourses, both Darwin and Bataille are the outer children of their times.

\section{No Methods, No Subjects}

The formalizing of historical trends in objectifying discourses is a trait of the child-like viewpoint that needs to ever order and reorder what is constantly a new world. Not merely 
the results of this reordering, but the very manner in which it is accomplished, becomes yet more accomplished over time, just as child-like notions begin to appear childish in the eyes of older children. Yet as we age older still, we also begin to realize that we cannot simply discard everything we had thought we had known. new knowledge only has meaning in relationship to what had come before it, just as we also judge our predecessor's abilities by our own. Speaking of Mill, Feyerabend reminds us that by the mid-nineteenth century, radically empirical method used in the light of historical knowledge was strong enough to be able to found an ethics: "He advised researchers not only to retain ideas that had been tested and found wanting but to consider new and untested conceptions as well, no matter how absurd their first appearance." (op. cit. 33). Creativity and constraint as ideals, the one seeming liberating and the other seeming enslaving, should take a step back from the processes of knowing, of 'finding truth'. Since truths were themselves lacking in ideal or absolute character we should then be led to enshrine methods scientific or philosophical in the same ideal realm that truths were once thought to inhabit. Indeed, this manner of putting a halo around truth led directly to the conception of a rationality that could stand beyond both cultural context but also the task at hand, a reality that involved the actions of the day to day, and the intentions of persons sundry and diverse. Such efforts did not approach either pole of freedom or slavery, the first completely and radically liberated from the inertia of history, the second utterly within its grasp. We could not "...admit that the principles were therefore 'freely created by the human mind', and rightly so, for there are many constraints beyond those allegedly imposed by logic, and 'rational' action not merely attends to these additional constraints but is also carried along by them." (ibid:212). It is not enough to suggest that limits are those which preponderantly lie within the system of reasoning used by this or that science, the type of logical justification given an argument or a theory, or even the epistemological sub-structure of the discourse in question. The order of the day bends itself further to the order of the day to day.

Within this second aspect of the outer child, discussions of apparent rationality rarely exceed the boundedness of the interiority of the intellect. Reason 'alone' is believed to be a viable reality. The following is typical of the recognizance that the way one thinks has a major influence on what one seeks and finds in science and philosophy, but there is no sign that this is just a beginning. The critique of objective standards of thinking is recognized to be a mirage, but what replaces it is a tighter more controlled form of logic which is ad hoc and participates in falsifiability, rather than a realization that the surrounding and existential envelope of history and culture impose their templates upon us at every moment, and the very notions of creativity and imagination are heavily conditioned by them. It is almost as if we can escape history by merely remembering that reason is mutable and cannot in any single guise remove the 'problem' of the subject: "Yet this defeat of subjectivity seems hollow because the propositions that are objectively found to be true are determined by styles of reasoning for which in principle there can be no external justification. A justification would be an independent way of showing that the style gets at the truth, but there is no characterization of the truth over and above what is reached b the styles of reason itself.' (Hacking, in Hollis and Lukes, 1982:65). However limiting this critique is, it is itself a 
necessary beginning. Reason, bereft of its own unreason, creates its own pedestal. This or that 'style' might well remind us that one can sculpt statues in different forms or reflecting different fashionable aesthetics. All of this is also the case, as what science and philosophy has found interesting or important over the centuries or millenia has often dramatically changed. But what is of the moment in the internal critique, that which is leveled at the objectified subject not by the child self as the letting loose of a new kind of reason that knows itself as unreason but as the outer child that is told to adapt to new external circumstances, is that this demand runs headlong into the problem that subjectivity itself attempts to resolve. The subject fills in the space of the object, not only as a guise of an object in the object realm, or as a set of social roles and statues in the cultural world - which also includes objects as artifacts and social role performances as artefacts - but also as its own language of positing itself. The subject still insists on the 'I am' in spite of the evidence to the contrary, the thickly languorous atmosphere of objectification, the energy expended on objection (to the politics of being an individual in a mass society, for instance), and the wasted resources of subjection (wage slavery or labor masquerading as 'work', for example). It is this insistence that suggests that after the subjectivities of the subject are removed - its excesses of the energy of self-positing - there remains the very space the subject has attempted to fill in with the presence of itself as a self. If we lose "...all the fullness of experience present in the way individuals are 'living' their subject-positions, what remains is an empty place which was filled out by this richness; this original void, this lack of symbolic structure, is the subject, the subject of the signifier." (Zizek op. cit. 197 italics the text's). One would question, however, if we ever do lose this 'richness'. We might not have to expose ourselves as linguistic occupants of an abyss of meaning to have the awareness that we must live on because life fills in the space of death. The sardonic smirk of such a realization appears on the face of only the cynic, and not the person who endeavours to become fulfilled through this or that life. The richness, in other words, really is rich for us, and cannot be entertained only as a manner of filling in the days, as a cleft upon which one can hang one's being or shelter against the storms of nothingness, but by which one can get nowhere, climb not higher, gently lower oneself to the safety of home and hearth that we might well imagine we can observe, at a great distance, form the black cliffs upon which we are pinned.

Just because the world shows, in time, that all methods are at least relative to a very specific context, that all ways of doing and knowing are related intimately to ethics and do not descend from morality, does not mean that one not only carries on in the sense of the thin red line, the skein of life-blood that drains into the common lot of existence long after the sutures of sociality have come out; a dementia demanding our dross as well as our wit and intelligence as its sacrifice. Rather, one is confronted by the creativity of the world, and one can respond in kind. For we are first and foremost, of that self-same world that exposes us as grains of sand while at the same time runs up against human history as the history that changes the world. Water appears to always have its way with beaches, but what is sculpted has its own merits, and the course of liquid must find its way around and inside them once again. In order to understand the dance of world and being, the movement of apprehension cannot exclude apprehensiveness, but through this, and perhaps to a certain extent, because of 
it, we look for our chances and take them as they come: "There is no one 'scientific method', but there is a great deal of opportunism; anything goes - anything, that is, that is liable to advance knowledge as understood by a particular researcher or research tradition. In practice science often oversteps the boundaries some scientists and philosophers try to put in its way and become a free and unrestricted inquiry." (Feyerabend, op. cit. 36). The same may be said of living in general, and why should the serious discourses of the mind be any different in this regard from any other form of life? Transgressions of social mores indeed are said to keep the meaningfulness of such rules current. Traditions are lived and thus also are living. The dead live again through archaeology, history, or memory. There is no experienced death but a living death, and once again, to realize this and smirk is to remain only cynical, to take no action whatsoever simply because the ends of all human action end the same way. There is a skipping over the life of humanity, an ignoring of its history. In doing so, we impoverish even poverty; not the romantic 'dignity' that it is said to embody, but the experience of its being in a world that is also full of riches of all kinds. All of us are poor in some way or other. All of us lack the demands of the outer child, or if we have given ourselves over to them more or less completely, we exile ourselves from the subjectivity that can embody aspects of the object realm, take them into our being and experience their captivity as part of the set of risks that freedom has been said to both acquire and need.

\section{The Grounding of Belief in Naivete}

The third aspect of the externalizing of the reasoning demands of what at first appear unreasonable to us is the naivety within which we surround our beliefs. To excavate this cloak, to examine its threads and the manner in which its weave shades us from our own shadows, "It is really a question of finding how unconscious values affect the very basis of empirical and scientific knowledge. We must then show the mutual light which objective and social knowledge constantly sheds on subjective and personal knowledge, and vice-versa." (Bachelard op. cit. 10). We also must attempt to comprehend the manner in which one changes into the other. Objectivity is the result of shared meanings, but how can meanings be truly 'shared' if they are but the sum of diverse subjectivities, the differences amongst these already having been admitted by the very concept of objectivity? The child self resists the objectification of the subject, as we have seen. But the outer child is the projected subjection of the subject to the object. It is the adult self's version of its own childhood placed back into the world of objects, as against a possible world of objections. This kind of projection guards against the child-like phantasm of the possible world. Such worlds as are dreamed by our waking child selves regularly graduate from the realm of the fantastic into their own reality, which is only obtruded upon when an adult calls forth the object world and forces it into confrontation with the dream. In this manner do the dream of children get put on hold. it is well known, e ourselves can recall, how we returned to this or that world of make-believe after the interregnum fostered by the object realm and its adult sociality. This motion is also 
an example of the reasonableness of a rationality which is creative and not instrumental. Yet the work accomplished in these 'waking dreams' cannot be recognized by the object world, and indeed, we may say that the rationality of the world of everyday wide-awake adult reality objects to a too generous accounting of childhood. The dreams must stay in their place, they should be a specific scene but not large enough to be a herd. This objection to the untrammeled subject of the child self means that this self is pushed in two directions; it must move sub rosa and later reappear metaphorically to cut the fetters of objectification, while at the same time its image is placed at a safe distance. In this way we can have our child within ourselves and yet still imagine we see ourselves in this light. Either way, the child self and its unreasoning reasonableness can mostly be ignored. This is necessary to further the production and reproduction of material social reality. For "The character of human life changes the moment it ceases to be guided by fantasy and begins to meet the demands and undertakings that ensure the proliferation of given works." (Bataille op. cit. 45). The problem arises only when the conception of one's work turns into mere labor, as Weber has famously shown in his genealogy of the spirit of capital. Assignation becomes mere assignment, mission becomes mere motion, acts become only action, and works, as in Werke, become the drudgery of 'going to work', as in Arbeit. The purpose of work was to live, and not the 'live to work' world in which most of us are now ensconced. All of this does not bear further comment, but it should be recalled that we have adopted this new set of beliefs without jettisoning the naivety associated with the original acceptance of both the calling and its source. That is, we must believe that our labor will amount to something, even if it is some years of retirement when we can turn our backs on what our life has been up to that point and sigh.

These points up the general problem of the outer child and its works. In the same way as does the subjectivity of the child self construct worlds and build things into them - the architectonics of toys which are not toys, such as Lego, for instance, bears witness to this act of creation in the light of the wider adult world of objects - the outer child retains the naive sense that what it constructs is both unique and of its own merit. This may in fact be the case, and of course, it is difficult to make an ultimate judgment to this regard, for it would depend almost entirely on not only our 'unconscious values' but are very conscious and judgmental beliefs about our own labor and that of others. The mark of the projected child of the object realm is its inability to separate itself from its labor and its results. The interiority of the child self simply no longer constructs things, and this is one reason why it attempts, during crises of conscience or even of consciousness, to tear things apart. We are forced then to distinguish between the beliefs 'in ourselves' as it is casually called, and beliefs which we know are shared by many in the adult social reality of the object world. But 'personal beliefs' are an oxymoron. There are no such concepts. What is private and personal are of the rank of opinions that might be shared but do not have to be, and whose meaning is transient. Their hold over us tends towards the trivial and when they are changed, there is no great ululation associated with the loss of the old and the acceptance of what replaces it, as long as this latter is itself of the same form, that is, of the opinion and its limited scope. Rather, beliefs are that which binds a society, and not a person. They are objectifying, objectifiers, as it were, 
because their significance as signifiers tends toward meaning construction that ascends to the level of the many and thus disassociates itself from specific view of the subject, even those this self-same source has also been objectified to a great extent by what has been previously thought of as belief. Though 'everyone' might be entitled to his opinion, the same cannot be said of belief, otherwise there would be no sense of crimes against humanity, or hate crimes and the like, as well as the lack of temples devoted to agnosticism, at least in some traditional religious form. We are also aware that beliefs, though shared, are not imminently shareable, as others hold different beliefs, and cross-culturally, no belief is ultimately shared in its entirety by all human beings. Therefore, belief one the one hand is merely objectified opinion - this is generally what rational discourse thinks of it - yet on the other hand, belief is also and at once the remains of the subject in the object realm. This remanence no longer has the content of childhood, but it does retain its structure, in that to believe in something requires a naivety that adults usually do not consciously allow themselves, hence the relevance of Bachelard's comment above. The force of both the child self's continuing interior presence, as well as the confrontation with other cultural traditions and contexts which appear to generate not humans as we have known them but aliens in the guise of a modified humanity, tends to disperse conscious knowledge and turn it into a surreptitious form of faith. We have worked diligently to rationalize this faith in philosophy and the social sciences by admitting to a variety of factors that would account for the striking differences of human belief systems: "Belief is relative to...well, what? [ ] Uncontentiously, beliefs vary with natural environment, as does the boiling point of water, and it is no surprise to find people who live in different climates taking suitable interest in their surroundings.' (Hollis and Lukes, 1982:11). Language both shapes and reflects this necessary interest, as peoples of all kinds adjust to where their happenstance birth has placed them. Further, the cultural context and tradition already present in all such spaces of birth immediately calls itself into action to pursue a new 'convert' until the very end of his or her existence. In doing so, beliefs come to be the conception about which orbits the cloud of rather vague understandings, and self-understandings, that inhabit the consciousness of living human beings, and in turn, evaluates their action in the object world of sociality and of things. 'Am I fitting in?' is the ultimate interrogative arbiter of social existence, replacing the ancient and organismic 'Am I fit?'

Beliefs may adhere or be sourced from anything at all, but those that are successful demonstrate their ability to adapt to the forces of change associated with the times. Their zeitung always thus bears the headlines of zeitgeist. Their rationality is unimpeded by mere traditionalism, for "...a clinging to old customs which have assisted survival in the past often has a rationality in the present, particularly in moments of immediate danger [ ] when it becomes vital and can be easily seen to be vital by the population as a whole to remain united." (Blackburn op. cit. 194). Thus they are also quite different in their scope and function form what Weber famously refers to as the effects of rationalization, which in his argument always differ from mere 'traditionalism' and to which, eventually, all traditional ritualism must defer. Rationality is a more portable conceptualization of action in the world than is rationalization. Even if both participate in the crucial distinction between rational action directed at finite ends and that directed to an absolute value, while apparently favoring 
the former, it is rationality that reaches out and adheres to what has been the case without seeking to rationalize it. This aspect of the outer child also has the naivety of belief. These beliefs have kept us together, we might imagine a state saying to its citizens, and they will continue to do so. United we stand, divided we fall, that sort of thing. There is no real philosophical rationality to any of this, but the pragmatism of the best case scenario reigns supreme. Of course, such a strategy may still be defeated if the crisis is thorough enough, but cultures can only do what they can do, as it were, and the politics of having everyone 'on board' or on side is at least a necessary first step. The problem that this kind of rationality often runs into is an ethical one, for instance, the sense that one can quickly create internal enemies with the prevailing political attitude of 'you are either with us or against us'. This alone may prove ultimately fatal for any in-group solidarity, as it slowly, even neurotically, picks apart its own networks. If there is an ethical gap in every morality which represents the difference between the ideal or principle and the social contexts and historical ethos in which decisions are to be made, there will be some kind of resistance to even the most practically minded rationality: "This certainly does not have to do with the resistances that our other preferences oppose to the moral demand, nor with the fact that psychic actuality will not yield itself to the realization of the Ought - rather, it has to do with the fact that life flowing forth as Ought, precisely because it is spiritual life, cannot escape from the latter's self-contradictions..." (Simmel, 2010:105 [1918]). We must indeed have more than a sense that morality or the social institutions - in their ideal or idealized forms - that emanate from it have some kind of clam on our existence that supervenes the more apparently immediate claims of the day to day or even local or regional kinships such as those ethnic or economic. No doubt it is difficult to convince everyone that this is the case, and as we have no real historical data from centuries receding rapidly from us regarding the amount of public let alone private loyalty shown by the masses to heir churches, states, or even manners of material exchange, we cannot simply say that this is a modern drift. However the case may be, the moral metanarratives of the ideal realm, including what is deemed to be divinely rational seek to reproduce themselves in understandable and immanent form. They must do so to compete with the immediacies and contingencies that persons in all cultures are already used to coping with form day to day existence. These supra-material forms demand that we eschew the mundane sphere - note that messianic demands in the face to face of proselytory encounters are of the same kind - in order to save ourselves from the crisis at hand, real or imagined, or generally, something of both. Morality and other deemed denizens of the very source of society and personhood suffer shipwreck not in times of crisis so much as they are slowly eroded by the vicissitudes of a more common history: "...namely, that the forms it produces and in which alone it can proceed to have a super-vital meaning and persistence, established by their own logic, against whose demand for regulation of life the steady stream of this same life - its inescapable differentiation, its restless content-change - resists." (ibid:105).

In this sense there is very much an internal conflict extant in every culture that has the potential for diversity their cultural practices. Such a diversity or pragmatism may be reflected in myth or morality, but to make the connection from the one into the other and 
thence back again in times that call forth the narratives of this or that living form of humanity requires the interpolation of vigilant interpretation, something the outer child is always short on. The projection of our objectified subjectivity rather prefers to live as it has lived, without regard for history, and this is reflected in the sliding character of rational methods of all kinds, most importantly for our own society, those of science. But as we have already seen, it is only when such methods aspire to become part of a metanarrative themselves do they sunder their pragmatic and flexible ties with the world as it is. They trade 'up' the living world for the world of myth, whereas in actuality "...there is no conflict between scientific practice and cultural pluralism. Conflict arises only when results that might be regarded as local and preliminary and methods that can be interpreted as rules of thumb without ceasing to be scientific are frozen and turned into measures of everything else..." (Feyerabend, op. cit. 38 italics the text's). The empirical attempt to measure the living-on of humanity is both bold and overbold. While one cannot simply pile up data that tend to flatten out over time - something that the fetish surrounding professional sports statistics might well be accused of - one also cannot presume that one has measured what one thought, or anything at all. The accumulation of masses of data is not so important in trivial realms of entertainment, but it does little to help us understand ourselves or the cosmos if we leave it at that in the realm of science. At the same time, 'laws' that are constructed from patterns that are themselves anthropomorphic once again attempt the trading up maneuver of instrumental rationality more generally. Personification could be seen as being traded for anthropomorphization, as it were. If scientism is the aping of overblown scientific methods - as 'the measures of everything else' and artism the similar fetishizing of the techniques of the 'great artists' and their periods and of the discourse of art history, then rationality betrays its desire for a kind or moralism that seeks ascension to the realm of super-vital morality. Even so, the same problem remains for the outer child of rationalized and projected subjectivity, the problem of human life, which ironically also includes, and refers to, the child self left 'behind' within the subject and by which the subject attains its own liberation within the object world. This freedom trades it's originally internalized, one might even say auto-objectified, fetters for those now more authentically autochthonous, co-constructed by the radical vivisection of one's previous lives never dormant. Given this, no mere statement, however serious and from whatever authority, could be said to entirely succeed within the interiority of the subject which has its own manner of objection to any attempted subjection: "The universal law cannot attach itself at all to inner processes insofar as these processes stand within an individual life-context, are only possible in this context, and are only the currently unfolding scene of the unitary life drama." (Simmel op. cit. 118). Why is this? Ideals and principles are lived, and have no separate existence that casts them up on any other shore but that composed of the grains of sand which we are. yet at the same time, they have a conceptual form which makes them distinct in our thinking from the ongoingness of life: "It embraces vital substance, not in the form of its becoming lived, but rather in the form of a conceptualized content that can recur as universal in every life-course and finds in each the same judgment deduced from moral law." (ibid). This is not mere neo-Kantian rhetoric. This notion of objectivity adhering to the things of the world and to ourselves at first as a thing in the world is relived as if it were real. Not only in its consequences, as Thomas famously asserts, but in its Being, the ideal objects and moral 
principles that populate our interiors more transiently than the child self - yet they are in some sense derived from and even to an extent form the very presence of that early version of the self - portray their essence through our existence.

\section{Subjective Rationalities?}

If this is the case, we would have to raise an objection to not only our objectification - the outer child mocks this kind of resistance as hypocrisy - but also to the cultural substance of our humanity, the moral suasion that bonds social relations within the subjectitude of the role-set. And we do just that. There is at once the unconscious, the child self, and the dignity, or egotism, of the adult self who is betrayed by the facade of collective conscience extant in rationalized social institutions and rational-legal authorities. Hence the fourth aspect that impinges upon but also shapes our reception of the projected objection to the subject consists of conflicting interpretations of rationality 'itself'. This projection also has within it its own set of resistances which take the form of publicly known or knowable parts of serious discourses - popular psychological self-help, for instance, or criminological statistics, economic 'indicators', and the madness of crowds - but we need look no further than to the undertaking of science itself to make itself known to the wider community. In doing so, it also attempts to be the undertaker of the unconscious and thus the re-animator of consciousness: "Scientific abstraction is the cure for the unconscious. Once it forms the basis of our education, it brushes aside the objections that are found scattered over the details of experience." (Bachelard op. cit. 64). We may debate the long-term merit of such experiences, including that designated as uncanny or even 'religious', but there is little debate concerning the sense that rationality can offer the correct and even the morally superior intelligence to combat the shadows of doubt. This in itself presents an odd ethical problem, because we would not rationally attempt to narrow the contrast of living to the point that life becomes otiose, giving rise to anomic alienation on top of the 'usual' structural alienations associated with capital. Even if James reminds us that the experience that is interpreted as extra-mundane, such as the visionary or mystical moment, has certain claim over the singular being of the one who has experienced it - at least in his or her own mind, at first - it has, just as absolutely, no claim over anyone else, we might pause and think that if we do reject another's claims to these regards, we might still wish to attain such experiences for ourselves. And we also do just that, but this time, after a fashion that speaks to us in an experimental language, and one within which the doubts of the non-rational and even the irrational appear as more than mere shadows: "Homo Sapiens, the rational species, whose intelligence enables if to choose through trial and error increasingly superior means to attain its ends, is persistently assailed by vampirish objects and agencies whose collective negativity can be designated as the predatory enemy of this rationality, the vampire of reason." (Blackburn op. cit. 22). ${ }^{\mathrm{i}}$ We must, in other words, find out for ourselves what not only others already know for like the mystical or visionary experience, the most mundane or instrumental of affairs lose their practicality in a translation that always must have some existential distance within it but also whether or not what others have known to be true really is what it claims to be; the truth at least in some viable and shareable sensibility. We can find out about the first easily 
enough, and all apprentices know this process well from one side, and thence from the other after their 'masterpieces' are completed. But the second offers itself to us only occlusively. We may seek so-called 'oceanic' experiences in order to prove the truth of truths to ourselves, though Freud and others famously remained unconvinced of their efficacy to this regard - or we may find the large within the small, the multitude within the intimate, through the sensuous and the aesthetic; "In such a form of life, claims of a purely sensuous existence become simultaneously newly audible in virtue of their dialectical differentiation from abstract universality and essentially recidivist in virtue of their drag on the development of spirit's autonomous relation to history." (Horowitz 2001:86 italics the text's). These experience, once had, both suggest to us that they are struck up in opposition to the thesis of the mundane, but at the same time they do not immediately grant access to the ideality of being that is desired as apart from this world and all its other forms. They also appear to have their own inner dogmatism, rationalized as a defense against the harrying hordes of the market: "The claims of concrete sensuous existence sound to the free rationality of abstract discourse like nothing but brute refusals to circulate in the world of fair exchange and compensation." (ibid). We do know as well that the dominance of current and globalizing economic institutions and their ideologies do not need every last one of us to in fact participate in any way. We might be their offal and their margins, but we do not have to be their foot-soldiers let alone their centers of power. Even so, aesthesis, the aesthetic experience as erlebnis, is too kindred with mysticism - they are like two tapestries hanging in the same metaphysical corridor - to be communicative in the manner our objection to rationality desires. The posited truth of truths must coexist with the living out of personal truth, even at the level of truism. All truism has an altruism to it in that it is willing to give away its potential profundity for the largest franchise possible. It trades depth for width. To look for one in the other can be frustrating, for the depths are inhabited by those 'recidivistic spirits' and the widths by everything either shallow or at best mundane. Once again, science has been seen to come to the rescue regarding this topological impasse, but there has been an ironic price-reward to be paid if we wish to exeunt the apparently turgid waters of living-on for the crystal pools of empirical insight: "As the discoveries become more widely known, blind admiration for Western science and for the 'rationalism' that goes with it gives way to a more differentiated, and, I would add, more humanitarian attitude: all cultures and not only the cultures connected with Western science and rationalism have made and, despite great obstacles, are continuing to make contributions from which humanity as a whole can benefit." (Feyerabend op. cit. 186). ${ }^{\text {ii }}$ Not unlike the nascence of various intellectual movements while discounting many of the self-interested ones began by disenfranchised intellectual classes in the archaic period of agrarianism, which only later, as Weber famously argues, become arenas for mystagogues and magical narratives when they are taken up by the masses - the contact amongst unlike cultures is likely to bring about the sensibility that at once our own society is questionable along structural lines - why do we do this and that, after all? - as well as being staunchly defended as the only possible society, or at least the only one worth living in. The rationales used to justify our current social reality quickly become our rationalities for the manner in which we think about the world itself. 


\section{Mll Macrothink}

Journal of Sociological Research

ISSN 1948-5468

2012, Vol. 3, No. 2

The projection of objectified subjectivity thus has this further relationship with rationality in that it can mistake and excuse for a reason. Outwardly liberated, but in reality orbiting the self due to a strong gravitational attachment to its more authentic interior - the outer child does not have its own center and thus cannot orbit in an autonomous axis - it finds itself constructing what appears to be a reasonable mode of coping with its public performance, a marionette upon which not all the strings are tightly attached and from which the loose limbs of lachrymose longing emanate. One key feature of this ill-constructed rationality that believes in its own reasons - unlike the reason of the interior of the self that knows unreason is its motive force, however sudden and short-lived - is a hallmark of capital, the fetishism of the object realm, whether as commodities - and everything can be made into a commodity or as things with which the personal museums of status and aesthetic are populated. Mementos, either mori or viva, provide the epitomes of this kind of gallery, the private archive of the auto-eskaton. This might be considered another form of the wasteful use of resources, but if no one else holds them to be of any value, their use in the construction of the self-possession of life may be forbeared. To this idea of possession, the possessiveness that breeds an acquisitiveness - or is it the other way around? - and its enchantment we will return shortly, but for the moment, we must realize that in comprehending the value of other cultural knowledge, or even of the other's knowing as a complement to our own, requires that we winnow what we consider to be the irrelevant aspects of this other existence into an understandable format. This means that the persona of the outer child "...misuses the negation he makes of the utility of the resources he wastes, bringing into contradiction not only himself but man's entire existence. The latter thus enters into an ambiguity where it remains: It places the value, the prestige and the truth of life in the negation of the servile use of possessions, but at the same time it makes a servile use of this negation." (Bataille op.cit. 73). The paradigmatic operation on the ever differing and deferring chain of signifiers is likely at the root of this sensibility; the syntagma of the object world is the sacrifice of the world in order to save the object. This is a cutting out, not a cutting loose, and in this another important difference between the outer child and child self is revealed. We may disdain the utility of reason and its objects - goals, values, and material things - but only the self in its unharnessed subjectitude, a subject that has been subjected to objectification but has found a way to object to its subjection, can then free itself from the servility of a life marginal to the consumptive productive forces of the day. What do those who drop from the common radar of commodity do with themselves? Do they attempt to produce alternative commodities in the hopes of creating a new market? Is this a negation of the servile use of possessions? Are there ten millenia of villages that house a thousand persons each attempting to construct a niche where their objects might be objectified, and thus their existence become an auto-subjection?

\section{Conclusion - The Possessed Character of Self-Possession}

There are no clear responses to such issues. One might well argue that things can be turned to the value of life rather than retain their character as tools for living-on. Yet even here, the syntagmatic cutting out of various forms of life - what neo-colonialism could compare to the 
trade of traditional societies, the Kula rings and potlatches? - is clear enough. 'Fair trade' cannot be fair in any historical sense, it simply appears to make the best of a very bad job indeed, and is rationale mocks the reason of unreason by buying into the self-destruction of what had been the case. In our own society and others, "These forms of destruction have threatened the very order at the heart of the progress of rationality. They constitute the vampire of reason in the negative sense of being corrosive of human, or indeed natural rationality. This very destructiveness has, however, had its creative side." (Blackburn op. cit. 212). It is not surprising to find that although our concept of nature has at its heart an order why else could our projected objection to mere subjectivity continue its own project of being systematically made again a subject to an externality that at length includes the cosmos? that supposedly is mimicked or even extended by the new rationality of intelligent and sentient consciousness. It would be far too radical a maneuver to suggest that humanity escapes the cosmic thread once and for all. Even the archaic metaphysics of transcendental godhead did not make this claim, but merely inserted the divine hand as a promethean catalyst. The idylls sung to origins as disparate as the market or to ancient alien visitation have also this same form. We do not demarcate ourselves form nature. It is our own evolutionary pedigree that has done so for us. Yet this passage too has an order that at least can be back-read onto our ancestry. We are always within the 'reach of reason', though reason 'itself' or 'alone' must escape both ourselves and the cosmos. Hence, ultimately "...truth and enjoyment are radically incompatible: the dimension of truth is opened through our misrecognition of the traumatic Thing..." (Zizek op. cit. 86). It is within the thing-hood of the thing to be unreasonable, as every object resists our complete understanding in the same as does our interiority. But this is, for us, a good thing, for we need the perspective that this resistance brings to our perception, for in it consists the very objectivity of human reason, the mode of being conscious that can examine itself from near and from afar.

This is why the subject can know itself as being both subjected to an object and come to object to this subjection. This is why rationality comes to be embedded within an apparently irrational aspect of the self, the child liberator who has its own reasons for its radical actions, and why we sometimes mistake our rationality to exist only in the set of rationales that are provided by the outer child who always seeks to excuse itself and its actions. For Zizek, "The Lacanian criticism of the autonomous subject and his power of reflection, of reflexive appropriation of his objective condition, is therefore far from any affirmation of some irrational ground escaping the reach of reason." (ibid). For us, the good we both see and seek in rationality might well hide itself within us under an irrational guise - irrational that is, only in hindsight, the child self is essentially pre-rational or, to speak of its ancestry within the inertia of the history of humanity and its understanding of how the world impresses itself upon us, non-rational in the sense of using 'magical thinking' - but nevertheless, it prompts us to self-reflection of the most intimate sort. It provides the ground of reason rather than escaping it. We can be critical of its efficacy only in the sense that it by itself cannot complete a philosophy of human existence, cannot complete its own subjectivity, for it has only the ability to see what is wrong with us, and not the foreknowledge of what objectification has given us; the status of being allowed to pursue ourselves to maturity as a being who has been 
deemed rational by the wider society. This is something no child has yet been given.

The final aspect of the character of the outer child concerns its ability to possess possessions, both in the archaic and somewhat superstitious sense of interfering spirits and the modern sense of owning things. On the one hand our projected and fully objectified subjection can be temporarily owned by other beings, real or imagined, while on the other it can in turn own its own menagerie of pseudo-beings in the world. Its dual abilities are, however, mere manifestations of the more radical powers we have projected along with it. The outer child, because it appears to us to be quite severed from the connection with subjective doubts, could well be the place where an ideal reason finds its home. Its viewpoint is objective, not only because it does not suffer the subject-object tension, but because it itself seems to be a mere object, another thing in the world of things, but one with a consciousness superior to that even of the quasi-object of aesthetic or scientific being. Its great virtue is that it appears to lack a conscience, as we have already suggested. From this absence, which is not temporary but part of the Being of projection in general, allows the outer child to house other kinds of being: "If one identifies the actual ego with Reason, with the Good, then it can only follow to write sin off as possession by the devil, who approaches us from without; he is the necessary correlate of that ego from which (as such) only good can come - for otherwise, whence comes the evil that is expatriated from ourselves?" (Simmel op. cit. 106). Surely there is irony in the thought that a vessel of objective reasoning also is the correct and even likely place for the presence of the malificent, or at least, the evil that is also plain 'banality', as Ernst Becker has identified it. For objectivity only occurs where there is no human conscience, or perhaps no conscience at all, for even a god would balk at being anonymously evil. The outer child, being separated from its parent and its previous self, is the space where such bedfellows might share their strangely impersonal intimacies. ${ }^{\text {iii }}$ It does not matter whether we think of these as the incubus or as pathology. Their interest is that they represent some radical otherness to the usual run of things, and to the usual kinds of people, who are forever uninteresting due to their own recognizance and subsequent adherence of normative life. The apparent liberation of the projected and objectified subject suggests to us that freedom also must involve the complete transgression of those norms whose source lies in our insinuated sense of the collective conscience. Bringing up to date being possessed only involved the possessed one possessing others, and it was de Sade who is generally thought of as being the writer who accomplishes this act: "Since he continued to be fascinated, however, precisely by rational questions of morality, albeit in reverse, his further implicit assumption [ ] is that human reason has an altogether other 'nature', knowing what is virtue and what is vice; the ambiguity of de Sade's position is that he justifies rationally what he knows to be unnatural..." (Thorlby, 1966:43). The major ethical problem in unbridled or self-interested sadism - that is, the sadist who lets loose without regard for another's suffering, or indeed, can only be himself if the other is not a masochist, for the presence of the masochistic relation would sabotage an authentic sadism - is that it seeks the subjection of the other without recourse to the potential pleasure or desire of the other. The other can only be a possession, and cannot remain with a sense of self-possession that allows jouissance of any measure. The sphere of the self's polar pleasure is the unfreedom of the other. 
The freedom that the outer child exhibits is, then, a false freedom, Though it is liberated from the social demands of the collective conscience and as such titillates our imaginations, its rationality implodes due to a consciousness that has no unconscious, and must fill this void with another form of being; the sudden irruptiveness of a demon, in archaic worldviews, or the banal anonymity of role adherence and 'bad faith' in our own. The recreation of the sadist is but a case in point. Freedom for the human being who is still humane in his consciousness always involves others as they are, resistant, almost impervious, obtrusive but not intrusive, challenging ourselves while knowing that we to are as to them as they are to us: "It is only in the sphere of freedom that they can engage in physical activity as a diversion, that they can speculate and play, that they can superfluously create and can gratuitously destroy, that they can live in order to be free." (Blackburn op. cit. 95). So freedom is never freedom from otherness, but only freedom from the other who seeks to be as the self already is, who, or what, seeks to infiltrate the other's self and further subject the child self to slavery while manipulating the adult self to become the strident voice of its own oppression. In fact, slavery does not ultimately destroy anything palpable, for if it did, there would be nothing to enslave. Rather, the oppression which a pure sadism, an 'unnatural' violence of the consecration to evil, brings on is the forced auto-sacrifice of all we know to be our own: "It does not have to destroy as fire does; only the tie that connected the offering to the world of profitable activity is severed [for the originating act of giving ourselves over to the sadist is shot through with our own vision of desire, our own sense that we too shall be set free by the act of (temporarily) losing power and control] but this separation has the sense of a definitive consumption; the consecrated offering cannot be restored to the real order." (Bataille op. cit. 58 italics the text's). The radicality of submission lies precisely in its denial of excess, while the reality that evil tears asunder is the measured discharge of excess. Whether 'effervescence of life' is the goal (ibid:10), and indeed, if this is a goal than such expenditure is not without purpose, not without the canniness of social solidarity, This is also why Freud famously suggests that the prohibition of incest was such a damaging retardant, the 'most drastic mutilation of the erotic life' (cf. Mendel, 1974:176). and it is that very life which is the closest to both the play of unhindered freedom - in the sensual love of the other and the self at once - and to the risk of both giving the self over to the other completely and utterly without recompense, and, conversely, the taking and possessing of the other without an reciprocating gift. Incest has within it all three of these estranged dimensions, as the sibling bond could be thought of as the union of equity, and the parent-child bond the union of inequity. Perhaps it is only the latter which should fall under on remonstrative gaze.

If the outer child is absolved form such deliberations, it is only thus due to its being absented from the normative bonds while at the same time attempting to represent the purity of reason without unreason. Just as selves are bonded through both social norms and through the subject-object imagination, the divorced being of the projected subject inclines itself only to the unarbitrated objection to its own being. It negates the subjectivity of the subject by objecting utterly to also being an object. That it has not the interiority to accomplish this task - it lacks both conscience and child self - suggests that it must remain within the instrumental 
rationality of anonymous social relations, and the banal rationality of a self-interest that has lost all interest in the self.

\section{References}

Bachelard, Gaston (1964). The Psychoanalysis of Fire. Beacon Press. [1938].

Bataille, Georges (1988). The Accursed Share, volume one. Zone Books. [1967].

Blackburn, Richard James (1990). The Vampire of Reason. Verso.

Feyerabend, Paul K. (1987). A Farewell to reason. Verso.

Hacking, Ian (1982). 'Language, Truth and Reason', in Hollis, M. and Lukes, S. eds. Rationality and Relativism. MIT Press, Pages 48-66.

Hollis, Martin, and Lukes, Steven, eds. (1982). Rationality and Relativism. MIT Press.

Horowitz, Gregg (2001). Sustaining Loss: art and mournful life. Stanford University Press.

Mendel, Sydney (1974). Roads to Consciousness George Allen and Unwin.

Thorlby, A. K. (1966). The Romantic Movement. Longmans.

Simmel, Georg (2010). The View of Life. University of Chicago Press. [1918].

Zizek, Slavoj (1990). The Sublime Object of Ideology. Verso. [1989].

\section{Notes}

\footnotetext{
${ }^{\mathrm{i}}$ What appears first as an object only from a gothic psychological romance has a transparent metaphor: "The vampire of reason, therefore, comprises not only the original destructive forces of nature, but also the predation of humanity on other species and on their common environment and the interhuman predation in imperialism and class domination." (Blackburn 1990:23). One might question the inclusion of 'nature' but we can suppose that the concept of nature is as cultural as our experience and interpretation of its effects, negative or salutary to our collective survival.

ii This sentiment also holds for periods of crisis or cultural conflict, and not mere contact, and the 'great obstacles' to which Feyerabend is referring are not necessarily of modern origin, although their force has been geometrically magnified in terms of their environmental impact and their geographic scope. Crisis as interpreted as bringing to the fore a kind of existential necessity, is proverbially the parent of invention: Even if the masses can on occasion benefit from foreign invasions, resistance to them can be quite rational and pertinacious." (ibid:60).

iii This is because the self, having a number of voices that demand justification for its collective acts, does not have room for the pure presence of anything. the self is rather always holding a séance with its own spirits, and no
} 
others need apply. Whether we are dreaming or thinking, the life of consciousness that amends itself in front of conscience is quite different than the rationality that immediately knows it can do something without respect to the ought: "We must regard our psychic life in each waking period as a continuously unfolding process and our consciousness of it as a fact comparable to no other, for it has not yet split apart into the knowing subject and the known, somehow objective content." (Simmel 2010:119 [1918]). 